Mundo Revista de agrario
Mundo Agrario, diciembre 2018, vol. 19, n 42, e098. ISSN 1515-5994

Universidad Nacional de La Plata

Facultad de Humanidades y Ciencias de la Educación

Centro de Historia Argentina y Americana

\title{
Relaciones sociales entre cuadrilleros y trabajadoras/es bolivianas/os en espacios de contratación informal. Estudio etnográfico en las cosechas agrícolas de Mendoza (Argentina)
}

\section{Marta Silvia Moreno}

Instituto de Ciencias Humanas Sociales y Ambientales, Consejo Nacional de Investigaciones Científicas y Técnicas, Argentina. Universidad Nacional de Chilecito, Argentina smoreno@mendoza-conicet.gob.ar

Cita sugerida: Moreno, M. S. (2018). Relaciones sociales entre cuadrilleros y trabajadoras/es bolivianas/ os en espacios de contratación informal. Estudio etnográfico en las cosechas agrícolas de Mendoza (Argentina). Mundo Agrario, 19(42), e098. https://doi.org/10.24215/15155994e098

Recibido: 31 mayo 2018 - Aceptado: 14 septiembre 2018 - Publicado: 07 diciembre 2018

(c) (1) (2) Esta obra está bajo licencia Creative Commons Atribución-NoComercial-CompartirIgual 4.0 Internacional

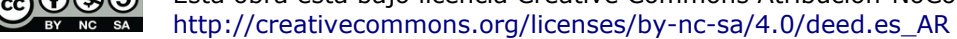




\section{Relaciones sociales entre cuadrilleros y trabajadoras/es bolivianas/os en espacios de contratación informal. Estudio etnográfico en las cosechas agrícolas de Mendoza (Argentina)}

Social relations between intermediaries and Bolivian workers in informal recruitment spaces. Ethnographic study in Mendoza (Argentina)'s agricultural crops

Marta Silvia Moreno

Instituto de Ciencias Humanas Sociales y Ambientales, Consejo Nacional de Investigaciones Cientificas y Técnicas, Argentina. Universidad Nacional de Chilecito, Argentina smoreno@mendoza-conicet.gob.ar

\section{Resumen:}

A partir de un trabajo de campo etnográfico efectuado entre 2009 y 2013, este artículo aborda las prácticas que entablan cuadrilleros y trabajadoras/es bolivianas/os en un espacio de contratación informal, en tanto mecanismos tendientes a articular intereses en pugna a partir de distintas modalidades de negociación. El trabajo de campo reveló que las condiciones de venta de la capacidad laboral se encuentran determinadas por el "precio del destajo", monto negociado en función del estado de las plantaciones y a partir de ciertos parámetros, como la cantidad y calibre de los frutos, y extensión de las fincas. Asimismo, puso de relieve que la demanda cíclica de trabajo daba lugar a momentos de "alta" y de "baja" en la demanda de trabajo, generando diferenciales capacidades de negociación entre los actores involucrados. La caracterización de estos procesos permitirá restituir la construcción de un mercado de trabajo local, que suple las necesidades de mano de obra de una agricultura diversificada, organizada mediante distintas lógicas y orientada a diversos mercados, para lo cual recurre a un conjunto heterogéneo de trabajadoras/es que convergen y se relacionan en sitios específicos y a través de distintas modalidades de intermediación.

Palabras Clave: Mercado de trabajo, Migrantes bolivianas/os, Cuadrilleros, Cosechas agrícolas, Mendoza.

\section{Abstract:}

Based on an ethnographic fieldwork carried out between 2009 and 2013, this paper deals with the practices that Bolivian workers and intermediaries keep in an informal hiring space, as mechanisms tending to articulate competing interests based on different negotiation modalities. The field work revealed that the conditions of sale of the labor capacity is determined by the "piece price", amount negotiated depending on the state of the plantations and based on certain parameters, such as the quantity and size of the fruits, and extension of the farms. He also remark that the cyclical demand for work gave rise to moments of "high" and "low" in the demand for work, generating differential negotiation skills among the actors involved. The characterization of these processes will explain the construction of a local labor market, which supplies the labor needs of a diversified agriculture, organized by different logics and oriented to different markets, for which it uses a heterogeneous set of workers than relate in specific places and through different types of intermediation.

KEYWORDS: Labor market, Bolivian migrants, Intermediaries, Agricultural crops, Mendoza.

\section{INTRODUCCIÓN}

La movilidad territorial entre Bolivia y Argentina es de larga data, ya que antecede la conformación de los estados republicanos de fines del siglo XIX (Pizarro, 2011) ${ }^{1}$. En Mendoza, estos desplazamientos se remontan a mediados del siglo XX y se han renovado desde entonces. Por el leve efecto acumulativo, en el último censo nacional efectuado en 2010 (INDEC, 2010), las/os migrantes bolivianas/os pasaron a conformar la primer minoría de extranjeros en la provincia, al alcanzar los 27.239 habitantes.

Una parte importante de estos migrantes se articuló desde su llegada como mano de obra estacional en las cosechas agrícolas, y se desempeñó en un mercado laboral segmentado para efectuar labores desvalorizadas 
en el contexto local, por resultar muy exigentes físicamente y ofrecer bajos salarios, en el marco de acuerdos predominantemente informales (Moreno, 2013; 2015).

A partir de un trabajo de campo etnográfico efectuado en un espacio de contratación informal, situado en un territorio con una proporción mayoritaria de trabajadoras y trabajadores procedentes de Bolivia, me propongo analizar las modalidades de negociación entre cuadrilleros y trabajadores durante la temporada de cosechas en Mendoza. Dentro de un mercado de trabajo en el que los intermediarios fluctúan y se modifican, los cuadrilleros, o gente "de confianza" de los diversos agentes empleadores, adquieren un rol fundamental para motorizar las redes de reclutamiento y, con ello, permitir que tenga lugar la negociación para acceder al empleo (Aparicio y Alfaro, 2001). En este marco, focalizo en qué se negocia y entre quiénes, así como las capacidades y recursos que se utilizan en cada caso. Estos resultados revisten interés ya que permiten poner de relieve el mundo oculto y cotidiano del trabajo a destajo en el que intervienen los trabajadores bolivianos, así como su capacidad de agencia; aspectos escasamente abordados por el sector científico en el estudio de la producción agrícola a nivel provincial.

Antes de proceder con este análisis, contextualizaré brevemente el mercado laboral agrícola de Mendoza y su vinculación con los procesos migratorios, para luego precisar algunas categorías conceptuales que guiaron la pesquisa.

\section{El CiClo de aCTIVIDADES AGRíCOLAS Y LA DEMANDA DE TRABAJO ESTACIONAL MigRANTE}

En Mendoza, la actividad agrícola se encuentra diversificada. La viticultura representa el $80 \%$, la fruticultura es la segunda actividad y representa el 8,9\%, seguida por la producción hortícola $(7,9 \%)$ y olivícola (3,2 \%)(DEIE, 2010 - 2011). Estas producciones han estado sujetas a profundas transformaciones en las últimas décadas (Neiman, 2010), lo que propició una mayor concentración de los factores de producción entre los grandes productores nacionales y extranjeros de perfil empresarial, que han sido capaces de interactuar en escenarios altamente competitivos (Pedone, 1999). Paralelamente, se ha tendido a subordinar y, en algunos casos, a excluir a los pequeños productores locales de estas actividades, manteniendo las condiciones de precariedad con relación a los trabajadores agrícolas (Berger y Mingo, 2012; Bocco, 2007a, 2007b; Neiman y Bocco, 2005).

De acuerdo con la encuesta sobre niveles de vida y producción (PROINDER, 1996-2003), existen 70.830 trabajadores agropecuarios en Mendoza, de los cuales menos del $20 \%$ son permanentes y más del $80 \%$ transitorios (Neiman et al., 2006, pp. 48-197).

Dentro de la actividad agrícola, las tareas para las que habitualmente se contrata fuerza de trabajo estacional son las de siembra, cosecha y empaque en el caso de las hortalizas; cosecha, raleo, empaque y poda en frutales, y poda y fundamentalmente cosecha para el caso de la vid. Como se detalla a continuación (Tabla 1), estas labores dan cuerpo a un ciclo de actividades agrícolas a lo largo de gran parte del año, al que se articulan los trabajadores estacionales (Moreno, 2017).

El conjunto de trabajos estacionales que demandan los distintos cultivos a lo largo del ciclo anual deben comprenderse aquí como una serie de posibilidades laborales para los trabajadores agrícolas, lo que no implica invariablemente trabajo seguro o continuidad a lo largo del año. Entre quienes se insertan estacionalmente ${ }^{2}$ en la actividad agrícola se encuentran los propios pequeños productores y contratistas de viña locales, trabajadores rurales, residentes de los centros urbanos y migrantes con variados proyectos migratorios, que arriban de provincias vecinas, del norte de Argentina y de Bolivia (Moreno, 2013, 2017).

En este marco, las formas de organización en el interior de cada uno de estos sectores, sumadas a las características biológicas propias de los distintos cultivos, dan por resultado que en determinados períodos se requieran cantidades extraordinarias de trabajadores para llevar a cabo actividades específicas, como las cosechas entre febrero y abril. Dentro de éstas, la de vid genera la mayor ocupación media a lo largo del año y ocupa la mayor cantidad de jornales (Fabio, 2010), dado que no se han introducido tecnologías 
mecánicas de forma generalizada (Neiman y Blanco, 2003). A modo de ejemplo, Bárbara Altschuler ha señalado que durante 2011 en Mendoza se necesitaron aproximadamente 16.000 cosechadores para levantar los 20 millones de quintales de uva producidos durante esa temporada (Alschuler, 2016).

Tabla 1: Ciclo de actividades agrícolas estacionales en Mendoza

\begin{tabular}{|c|c|c|c|c|c|c|c|c|c|c|c|c|c|}
\hline Sestor peoductive & Masidal ato & sontiantare & actation & Nade entare & Decheribue & Enmoro & Fobreme & Maras & ard & Maro & surlo & Mlo & santso \\
\hline \multirow{17}{*}{ HOKT AUZAS } & Cosectia die cebellia & & & & & & & & & & & & \\
\hline & Gosecha be ajo mor atio & & & & & & & & & & & & \\
\hline & 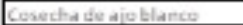 & & & & & & & & & & & & \\
\hline & 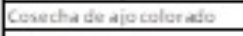 & & & & & & & & & & & & \\
\hline & $\begin{array}{ll}\text { Conechat bimatse } \\
\end{array}$ & & & & & & & & & & & & \\
\hline & \begin{tabular}{|l|l|l|l} 
Conecthased \\
\end{tabular} & & & & & & & & & & & & \\
\hline & 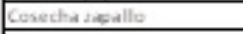 & & & & & & & & & & & & \\
\hline & 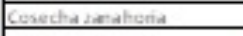 & & & & & & & & & & & & \\
\hline & 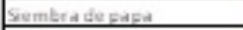 & & & & & & & & & & & & \\
\hline & 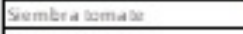 & & & & & & & & & & & & \\
\hline & 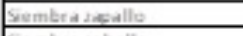 & & & & & & & & & & & & \\
\hline & 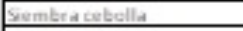 & & & & & & & & & & & & \\
\hline & Sembia alo menado & & & & & & & & & & & & \\
\hline & 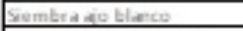 & & & & & & & & & & & & \\
\hline & Sembra alo colonato & & & & & & & & & & & & \\
\hline & 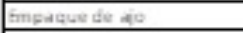 & & & & & & & & & & & & \\
\hline & Embeladico onbella & & & & & & & & & & & & \\
\hline \multirow{19}{*}{ FEUTALS } & Gesechta cinuela & & & & & & & & & & & & \\
\hline & 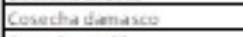 & & & & & & & & & & & & \\
\hline & \begin{tabular}{|l} 
Cosecha melće \\
\end{tabular} & & & & & & & & & & & & \\
\hline & \begin{tabular}{|l} 
Conechas send \\
\end{tabular} & & & & & & & & & & & & \\
\hline & 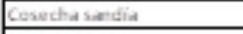 & & & & & & & & & & & & \\
\hline & \begin{tabular}{|l|l|l} 
Genechatunaing \\
\end{tabular} & & & & & & & & & & & & \\
\hline & 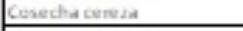 & & & & & & & & & & & & \\
\hline & 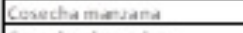 & & & & & & & & & & & & \\
\hline & 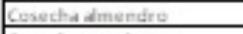 & & & & & & & & & & & & \\
\hline & \begin{tabular}{|l|} 
Gosecha rapal \\
\end{tabular} & & & & & & & & & & & & \\
\hline & \begin{tabular}{|l|} 
Conechta olivo \\
\end{tabular} & & & & & & & & & & & & \\
\hline & 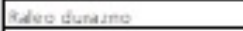 & & & & & & & & & & & & \\
\hline & 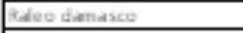 & & & & & & & & & & & & \\
\hline & \begin{tabular}{|l|} 
Reduo cinuela \\
\end{tabular} & & & & & & & & & & & & \\
\hline & \begin{tabular}{|l|l} 
Livo pena \\
\end{tabular} & & & & & & & & & & & & \\
\hline & 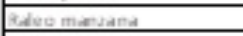 & & & & & & & & & & & & \\
\hline & 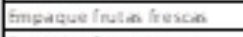 & & & & & & & & & & & & \\
\hline & 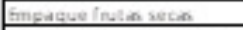 & & & & & & & & & & & & \\
\hline & 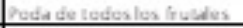 & & & & & & & & & & & & \\
\hline \multirow[t]{3}{*}{ vio } & \begin{tabular}{|l|l} 
Gosechtade vid \\
\end{tabular} & & & & & & & & & & & & \\
\hline & 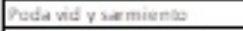 & & & & & & & & & & & & \\
\hline & 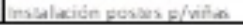 & & & & & & & & & & & & \\
\hline
\end{tabular}

Fuente: Elaboración propia con base en información proporcionada por la

Subsecretaría de Trabajo y el Instituto de Desarrollo Rural (IDR), 2010/2014.

Durante los mismos meses del año se intensifica además la demanda de trabajo para otras actividades estacionales en las producciones de frutales y hortalizas, lo que genera una importante competencia por la fuerza de trabajo disponible entre los diferentes sectores y actividades. En este contexto crece el peso relativo del aporte de mano de obra migrante que se traslada estacionalmente a la provincia.

Para analizar las relaciones sociales entre cuadrilleros y trabajadores bolivianos ${ }^{3}$ en el contexto que acabamos de caracterizar precisamos detenernos un momento para especificar algunas categorías conceptuales.

\section{Algunas precisiones teóricas sobre SEgmentación, trabajo a Destajo, INTERMEDIACIÓN LABORAL Y MODALIDADES DE NEGOCIACIÓN}

Partimos de entender el trabajo en un sentido amplio, como resultado de la imbricación de procesos productivos y reproductivos que anudan y ponen en diálogo relaciones sociales concretas entre diversos actores sociales (Moreno, 2017). En particular, focalizamos sobre el trabajo estacional en las cosechas agrícolas de Mendoza, una modalidad de trabajo remunerado que se efectúa a cambio de un salario. Sobre la base de la teoría de la segmentación del mercado de trabajo (Pries, 2000), partimos desde el supuesto de que el mercado de trabajo agrícola en Mendoza es heterogéneo y desigual, e incluye dos sectores: uno primario, que engloba las actividades calificadas de profesionales, como ingenieros agrónomos, enólogos, licenciados 
en comercialización y en recursos humanos, que perciben salarios más altos y mayor estabilidad laboral, y uno secundario, que presenta una creciente inestabilidad laboral, salarios más bajos y condiciones laborales precarias y peligrosas, desempeñadas por trabajadores estacionales de menor calificación, en el que existe una amplia presencia de migrantes bolivianos.

El sector secundario del mercado de trabajo agrícola se articula tanto con los enclaves étnicos en la horticultura (Benencia, 2008), con pequeños productores familiares y contratistas de viña y frutal, así como con otras modalidades de organización de la actividad laboral, entre ellas, bodegas y empresas agroindustriales que demandan mano de obra estacional para las actividades ya reseñadas.

En todos los casos, para los trabajadores bolivianos, las jerarquías laborales están atravesadas por diferenciaciones entre nacionalidades: las actividades vitivinícolas y frutícolas fueron desarrolladas por inmigrantes europeos y afianzadas por sus descendientes, algunos de los cuales todavía se mantienen como propietarios con larga trayectoria. De ellas, la vitivinicultura es la producción que nuclea la mayor cantidad de hectáreas cultivadas, junto con una importante proporción de productores capitalizados y de perfil empresario (entre ellos algunas inversiones internacionales incorporadas en las últimas décadas), mientras que la fruticultura se posiciona como la segunda actividad y mantiene un perfil mucho más heterogéneo entre sus productores, que va desde empresarios hasta pequeños productores familiares.

Por su parte, la horticultura fue iniciada tempranamente por los migrantes españoles, que fueron remplazados por migrantes bolivianos entre las décadas de 1960 y 1970 (SAF, 2016). Esta actividad se practica en todos los oasis de la provincia, con características similares a las señaladas por Ciarallo (2014) para los productores del Alto Valle de Río Negro, que realizan una horticultura intensiva en pequeña escala (parcelas menores a $5 \mathrm{ha}$ ), diversificada y orientada al mercado interno. En Mendoza constituyen el $70 \%$ de los agentes productivos definidos como productores familiares y en transición (IDR, 2006), mayoritariamente de origen boliviano. Pero la provincia cuenta además con áreas de horticultura especializada y extensiva para el cultivo de ajo morado, blanco y blanco temprano, cuyo destino es el mercado externo. Este sector es comandado por un grupo de productores grandes y empresarios de origen argentino o brasileño, y en menor medida, descendientes de bolivianos que nacieron en Argentina. Los migrantes bolivianos, en cambio, se insertan mayoritariamente como trabajadores permanentes o temporarios de aquéllos.

Otra característica importante de este sector secundario del mercado de trabajo local es que se organiza alrededor de diversas formas de intermediación laboral, donde destacan los "cuadrilleros" que facilitan los distintos mecanismos de "enganche". Éstos pueden ser migrantes bolivianos pertenecientes a cohortes migratorias anteriores, o bien trabajadores locales o migrantes internos. El rasgo característico estaría dado aquí en que previamente se han desempeñado como trabajadores estacionales, es decir, por su posición de clase. En este sentido, algunos autores sostienen que los cuadrilleros proceden de la clase trabajadora agrícola estacional - poseedores de su mismo origen de clase y condición social (Moraes Silva, 1999) - y operan en calidad de intermediarios para facilitar la provisión de trabajadores. Esto se realiza a partir del manejo de redes de contactos en los barrios y poblados de trabajadores estacionales, e implica, además, la función de traslado y control de la fuerza de trabajo en los campos de cultivo (Sánchez Saldaña, 2001).

Asimismo, con relación al rol que cumplen en los procesos de reestructuración del capitalismo agrario, Génova (2006) afirma que los "enganchadores" resultan figuras centrales en el análisis de los procesos de formación de una fuerza de trabajo adecuada para determinados sistemas de explotación intensivos (Benencia y Quaranta, 2006), como los que exhibe la agricultura de Mendoza. En una misma línea, Sánchez Saldaña (2001) destaca que la provisión de fuerza de trabajo inmigrante por medio de la figura de los cuadrilleros resulta sumamente provechosa para el sector patronal, debido no sólo a que se ajusta a los ciclos de trabajo estacional que no alcanzan a cubrirse con los aportes de fuerza de trabajo local, sino a que además estos trabajadores tienen predisposición para desempeñarse en tareas que, en general, resultan poco atractivas para la población local. De esta manera, la posibilidad de contratar trabajadores migrantes por lapsos de 
tiempo relativamente cortos permite al sector patronal contar con una fuerza de trabajo barata que asume parte de los costos de su reproducción y retiro (Meillassoux, 1985). Kearney (2008) dirá en este sentido que estos sistemas de trabajo son económicamente ventajosos para las economías receptoras, "no sólo porque la mano de obra barata se les entrega por sí misma, sino también porque los costos de reproducción y retiro de dichos trabajadores recaen sobre economías de regiones distantes y distintas" (2008, p. 103), o, agregaríamos nosotros, sobre los mismos trabajadores.

Definimos a las cosechas de Mendoza como un mercado de trabajo local que se construye alrededor de la oferta de trabajadores estacionales asociados a procesos migratorios ${ }^{4}$, en el que las redes cumplen un papel fundamental en la materialización de los desplazamientos territoriales y en la transmisión de la información, pero no así en el acceso seguro a un puesto de trabajo en el momento de arribo. Por estas razones hablamos de segmentación del mercado laboral o de conformación de "nichos laborales para migrantes recientes", que se caracterizan por "reproducir de manera cíclica algunas franjas del mercado laboral [sector secundario] por el constante arribo de nueva fuerza de trabajo migrante" (Herrera Lima, 2005, p. 168).

En referencia a estos aspectos, numerosos autores (Meillassoux, 1985; Morberg, 1996; Herrera Lima, 2005; Wolf, 2005) sostienen que este tipo de segmentación de la fuerza de trabajo, que ordena jerárquicamente a los grupos y categorías de trabajadores y que recrea continuamente en el nivel simbólico diversas distinciones culturales (étnico-nacionales, raciales, de género, entre otras) resulta central en la acumulación capitalista. Esto se debe a que constituye una forma de regulación sociocultural, por medio de la construcción social de identidades laborales, que naturaliza cierto tipo de contrataciones y condiciones laborales sumamente desfavorables para los trabajadores, que además intensifican su vulnerabilidad debido a la irregularidad en su condición migratoria (Pizarro, 2010).

Esto se ve reflejado en Mendoza en la construcción de un estereotipo sobre los migrantes bolivianos, que los califica como los trabajadores más aptos para desempeñarse en la agricultura, por ser tipificados, entre los dueños de los medios de producción y los cuadrilleros, como "más trabajadores y menos problemáticos" que la mano de obra local, aspectos que justifican la segmentación étnico-nacional del mercado de trabajo agrícola estacional (Moreno, 2015).

En este marco, para analizar las relaciones sociales entre trabajadores migrantes y cuadrilleros en los espacios de contratación informal, nos valemos del trabajo de Torres (1997) sobre los trabajadores tomateros de Autlán (México). Allí el autor describe el funcionamiento de esta industria como un ambiente de relativa inmoralidad y cumplimiento mínimo de la ley, "donde los derechos, demandas e intereses de los trabajadores, de los intermediarios y de los patrones son objeto de negociaciones constantes" (Torres, 1997, p. 279). Estas reflexiones resultan de vital importancia para cuestionar la hipótesis central de muchos estudios sobre trabajadores, que desde una perspectiva neoclásica dan por supuesto que las relaciones o juegos de poder entre patrones y trabajadores son siempre y simplemente desfavorables para estos últimos. En consecuencia, se reproducen irremediablemente imágenes conceptuales que representan a los jornaleros agrícolas como seres inmersos en un medio social alienante, que determina el constante deterioro de sus estándares de vida familiares. Si bien no pueden ignorarse los aspectos de crueldad y explotación, es preciso reconocer que las condiciones de trabajo representan también un ambiente flexible y espontáneo, "por lo que puede resultar más útil analizar lo que hacen los trabajadores y ver cómo atribuyen diversos significados a sus vidas” (Torres, 1997, p. 36). Para ello, apelamos al concepto de la agencia humana (Giddens, 1979) que permite identificar las capacidades transformativas de las prácticas, para poner de relieve la manera en que los trabajadores logran cambiar el margen de diversidad que puede ampliar o limitar las condiciones sociales en las que viven ${ }^{5}$.

Dentro del amplio margen de relaciones y prácticas sociales entre cuadrilleros y trabajadores, por razones de espacio, en esta oportunidad focalizaremos en las modalidades de negociación laboral en un espacio de contratación informal. A partir de las investigaciones de Alfaro (1999) y Tomada y Rigat-Pflaum (1998), suponemos que toda teoría de la negociación laboral lleva implícita una teoría del conflicto, y que ambos procesos, de negociación y conflicto, forman parte de las relaciones entre las personas, grupos e instituciones. 
Más específicamente, estos autores plantean que la negociación laboral puede pensarse como un canal de resolución provisoria de los conflictos entre actores con intereses divergentes que se vinculan en el mercado de trabajo.

Uno de los aspectos centrales alrededor del cual giran las diversas prácticas de negociación en los lugares de enganche es la definición del "precio del destajo" (Rau, 2005). Marx (1986) sostenía que el salario a destajo es una de las modalidades de pago que mejor cuadra con el modo capitalista de producción, porque permite reducir el salario y prolongar la jornada laboral. No obstante, el pago a destajo no es más que una forma "transfigurada" del pago por tiempo, dado que el salario por unidades de tiempo se mide por la duración directa de éste (cantidad de horas de trabajo), mientras que en el salario a destajo se mide por la cantidad de productos en que el trabajo se condensa durante un determinado tiempo (cantidad de piezas o unidades de producto). A pesar de esta diferencia, el autor argumenta que ambas modalidades salariales son idénticas en el sentido de que producen plusvalía a partir de la diferencia entre el trabajo remunerado (salario pagado al obrero) y el trabajo no remunerado o excedente (plusvalía que queda en manos del capital).

Hasta aquí hemos presentado una plataforma conceptual que nos permitirá avanzar en el análisis de los datos que componen este trabajo. Antes de ello realizaremos algunas precisiones sobre nuestro abordaje metodológico.

\section{Estrategia METODOLÓgicA}

Los resultados que presentamos en esta oportunidad se basan en una investigación etnográfica efectuada en el distrito de Ugarteche (Figura 1). Esta localidad, ubicada en el extremo sur del departamento de Luján de Cuyo (oasis norte) y a $35 \mathrm{~km}$ de la capital de Mendoza, exhibe una mayor presencia histórica de trabajadores disponibles para insertarse en las distintas actividades estacionales que ofrece la agricultura provincial. Su poblamiento es de larga data, aunque comienza a crecer de forma sostenida a partir de 1940, hasta alcanzar los 6.603 residentes permanentes en el último Censo Poblacional (CNPyV, 2010), en su mayoría bolivianos y descendientes de bolivianos.

Figura 1: Distrito de Ugarteche, Luján de Cuyo (oasis norte), Mendoza

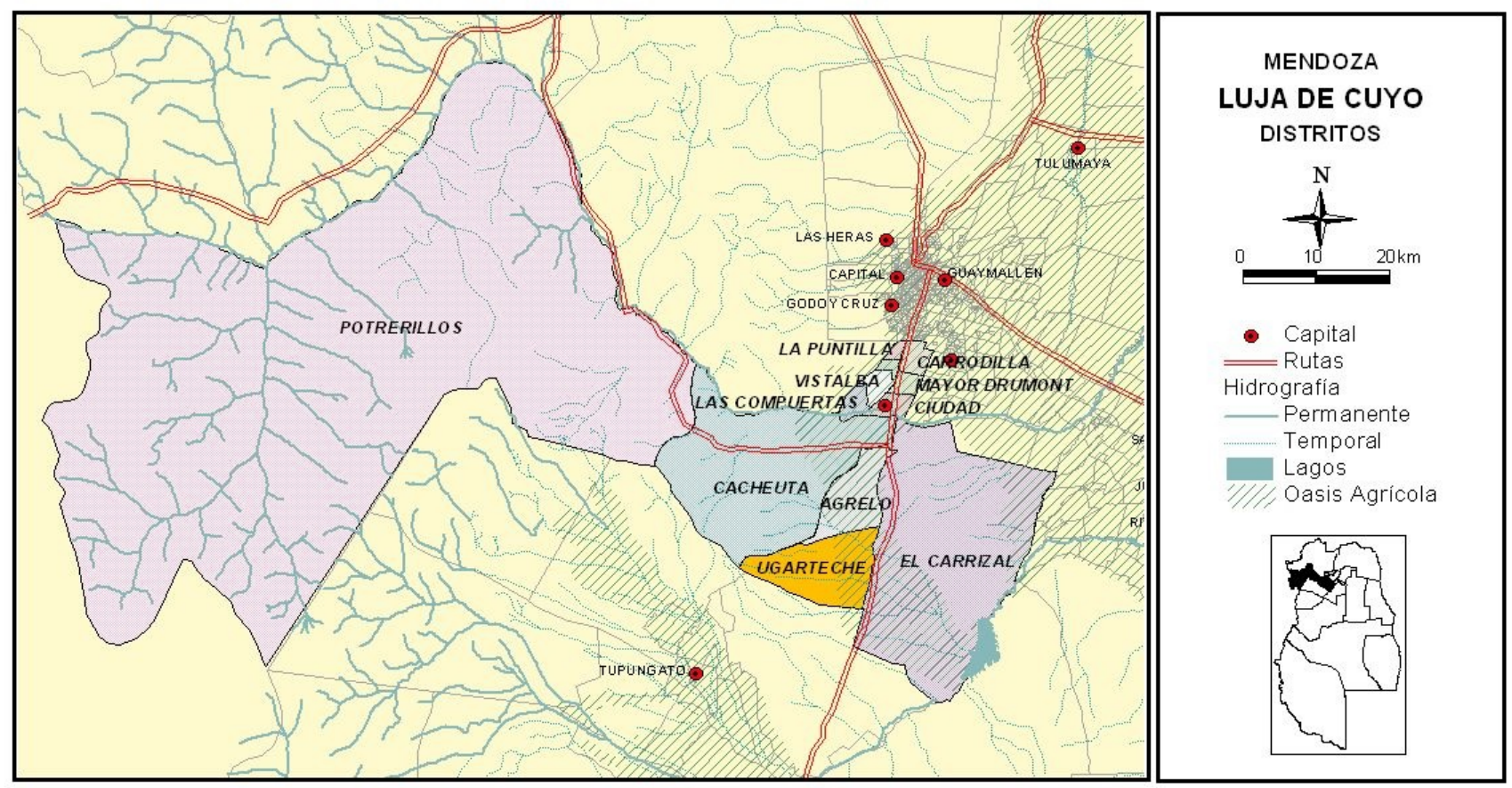

Fuente: SIG DESER, LADYOT-IADIZA, CCT CONICET Mendoza. 
Durante la década del cuarenta Ugarteche se convirtió en un polo de producción hortícola, impulsado por algunas familias procedentes de Europa que aprovecharon el tendido del ferrocarril y los canales de comercialización establecidos con Buenos Aires. Alrededor de esta actividad comenzaron a llegar los primeros trabajadores norteños y bolivianos durante la década de 1950, quienes se ubicaron en los márgenes de la Ruta Provincial $\mathrm{N}^{\circ} 15\left(\mathrm{RPN}^{\circ} 15\right)$. Desde entonces, la localidad creció y se expandió al ritmo de las posibilidades laborales en una agricultura diversificada, y de los flujos migratorios que por ellas se vieron atraídos. Si bien parte de sus habitantes ha residido allí por largos períodos -con hijos y nietos nacidos en la localidad-, en la actualidad también existen migrantes llegados recientemente y un gran número que permanecen sólo temporalmente por los períodos de cosechas que se suceden año a año.

Para llevar adelante el proceso de investigación, se adoptó el enfoque etnográfico de investigación sociocultural (Hammersley y Atkinson, 1994) y el estudio de caso como estrategia del diseño de investigación $^{6}$ (Denny, 1978). En éste se consideró como unidad de análisis la articulación de los migrantes bolivianos al mercado laboral agrícola estacional en Ugarteche, y como unidad de estudio, "la RPN¹5", es decir, el espacio donde se encontraban quienes buscaban trabajo y quienes buscaban trabajadores. La estrategia privilegiada fue la observación participante y las conversaciones informales con trabajadores e intermediarios que se reunían a un costado de la ruta desde muy temprano en la mañana. La prolongación del trabajo de campo en este espacio posibilitó además efectuar numerosas entrevistas en profundidad a informantes calificados ${ }^{7}$, seleccionados según un muestreo teórico que se elaboró mediante las técnicas de bola de nieve y la selección por redes (Hammersley y Atkinson, 1994), que cubrió a más de 30 de trabajadores y 29 intermediarios que se convocaban en el lugar ${ }^{8}$.

La presencia reiterada en la $\mathrm{RPN}^{\circ} 15$ hizo posible inducir que allí se articulaban principalmente trabajadores bolivianos e hijos de bolivianos (y en menor proporción trabajadores locales o norteños), así como intermediarios cuadrilleros (muchos de los cuales trabajaban de modo independiente y otros que, en menor proporción, se vinculaban con cooperativas de trabajo, empresas de RRHH o empresas agroindustriales). El carácter cíclico que exhiben las cosechas de Mendoza explica que en algunos meses, el trabajo de campo fuese particularmente intenso, especialmente entre septiembre y abril, momento en que se registraba la mayor afluencia de trabajadores estacionales.

\section{LA RPN'15 COMO ESPACIO INFORMAL DE "ENGANCHE" DE TRABAJADORES ESTACIONALES BOLIVIANOS}

Las múltiples intermediaciones presentes en el mercado de trabajo determinan que la negociación que se produce en el momento de la contratación se aleje de los estilos más clásicos orientados por el modelo patrón/obrero (Alfaro y Rau, 2005). En el caso de las cosechas, las negociaciones para acceder al trabajo se complejizan además porque se sostienen en múltiples acuerdos, con diverso grado de formalidad y entre distintos agentes. Los dueños, encargados, contratistas, chacareros o personal calificado de las empresas negocian ciertos términos y condiciones de contratación con los cuadrilleros (formas de pago, requerimientos de calidad en la realización de las tareas, responsabilidad y dirección del personal, entre otras), y éstos, a su vez, negocian con los trabajadores (el precio del destajo y los días de pago, las condiciones de trabajo y los requerimientos de calidad, entre otros ejes). "Los intermediarios son el cuadrillero y el ingeniero. El ingeniero contrata al cuadrillero y el cuadrillero nos contrata a nosotros. Muy raro el ingeniero que viene a buscar gente acá [a la ruta]" (jóvenes trabajadores hijos de migrantes bolivianos, $\mathrm{RPN}^{\circ} 15,2012$ ). A estas complejidades se agrega el hecho de que las condiciones sobre las que se fijan los acuerdos varían constantemente (Aparicio y Alfaro, 2001). "Ahora la cosecha es muy rotativa, porque depende de la calidad de la uva, la cantidad de uva y de la empresa también” (entrevista a cuadrillero paraguayo residente de Ugarteche, 2012). 
A partir de la observación participante efectuada durante el trabajo de campo y de las entrevistas en profundidad realizadas a los actores que participan en estos espacios, se ha podido constatar que las redes informales son altamente significativas. El reclutamiento es posible porque estas redes familiares, vecinales, locales y transnacionales operan fluidamente y encuentran espacios específicos de intercambio.

Esto hace que los caminos para emplearse en la cosecha sean muy variados, desde acceder por ser vecino de la finca, conocer a un jefe de cuadrilla, ser amigo de un conocido de confianza de un capataz o, como analizaremos en esta oportunidad, aguardar en un lugar específico -la RPN ${ }^{\circ} 15$ (Figura 2) - junto a otros potenciales trabajadores y buscar allí las mejores posibilidades laborales.

Durante el trabajo de campo en la RPN 15 , un cuadrillero señaló que "de acá sale gente para todos lados". Al preguntarle si preferían la gente de Ugarteche por alguna razón en particular, respondió: "No, justamente porque acá es el núcleo en donde se concentra la mayor cantidad de gente para hacer este tipo de trabajo, porque los mendocinos es muy raro que quieran trabajar en la viña, normalmente el trabajo de la viña no lo quieren hacer" (Cuadrillero, $\mathrm{RPN}^{\circ} 15,2012$ )

Figura 2: Ruta Provincial Nº15. Moreno, 2012

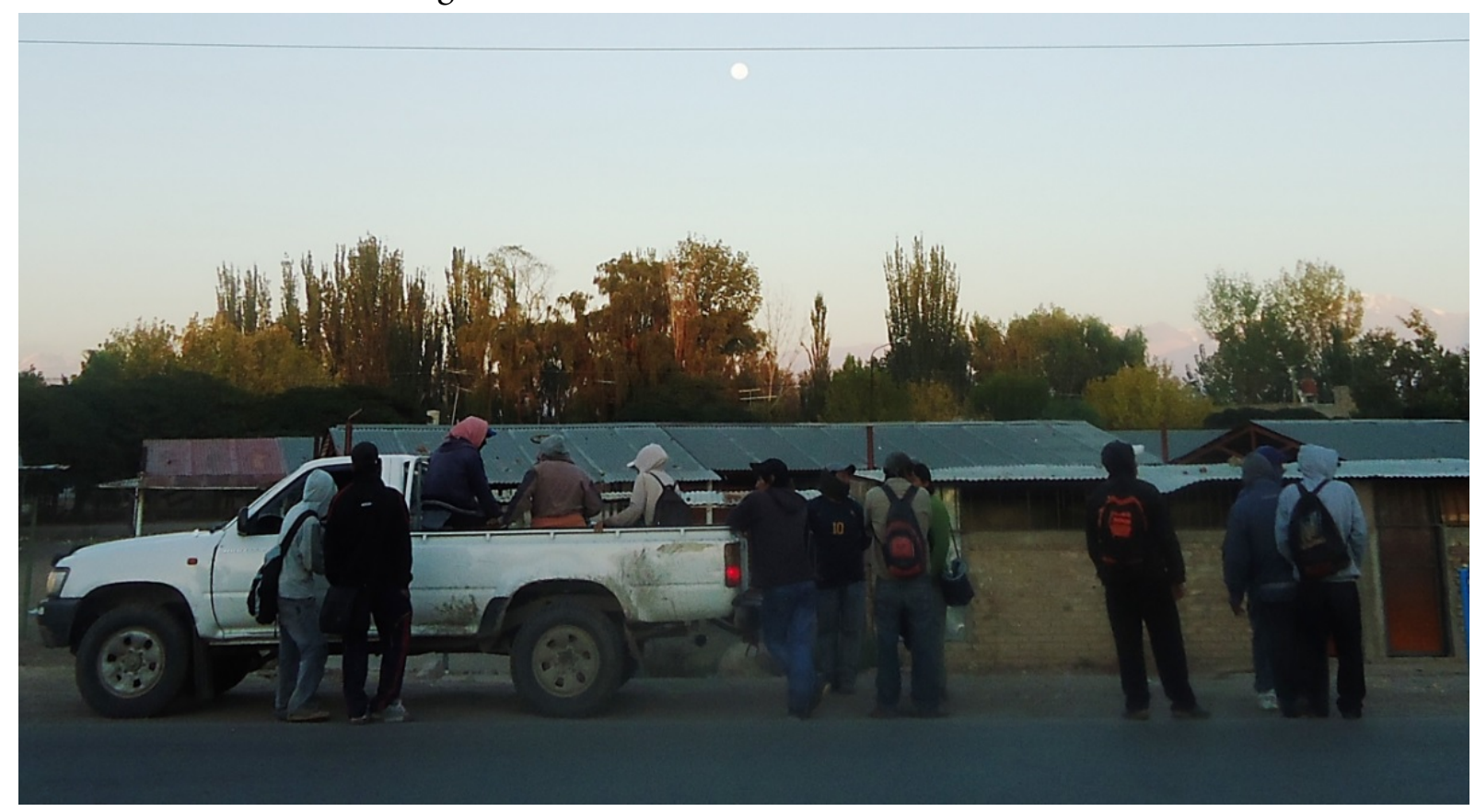

Los comentarios de éste y otros cuadrilleros pusieron de manifiesto el modo en que opera la segmentación del mercado laboral agrícola a partir de la fijación de espacios específicos de interacción en los barrios de trabajadores migrantes, donde se reúnen quienes buscan trabajadores "que quieran laborar en el campo" (en la viña), y los potenciales oferentes de fuerza de trabajo, en su mayoría bolivianos e hijos de bolivianos, como también migrantes de otras provincias argentinas, que están dispuestos a "hacer este tipo de labores". De este modo, el estereotipo naturalizado sobre los trabajadores bolivianos "muy trabajadores" adquiere connotaciones que van más allá de su supuesta adecuación para desempeñarse en el campo. Se remarca sobre todo la predisposición de los trabajadores que se concentran en esta localidad, para realizar tareas agrícolas que en general no resultan atractivas para los pobladores locales.

Durante todo el año, aunque con mayor intensidad en el período de cosechas, la RPN ${ }^{\circ} 15$ en Ugarteche cobra vida durante las mañanas. Entre las 5:30 hs y las 8:00 hs se congregan en este espacio una gran cantidad de trabajadores, cuadrilleros, contratistas y chacareros. Todos visten ropa de fajina, suelta, cómoda y resistente. Muchos utilizan gorras y pañuelos (“pañueletón”), sobre la gorra o debajo de ella, para cubrirse 
del sol. Algunos también se cubren el rostro y el cuello con pañuelos o remeras para amortiguar el frío matinal y evitar las picaduras de insectos y, entre los muy jóvenes, posiblemente para que no pueda notarse su edad.

\begin{abstract}
Allá está la ruta, ahí a las seis de la mañana, a las cinco y media ya están las Traffics, como ahora están con la uva, hay Traffics, camionetas que salen pa' todos lados (...) pa’ Medrano [entre Rivadavia y Junín, oasis este], San Carlos [oasis Valle de Uco], pa' todos lados, pa' todos lados te llevan las Traffics. Hay micros grandes también que llevan, esos también llevan gente... ¡uff! vas a ver Traffics, camionetas, colectivos, hasta en camiones llevan gente (...) ¡oh!, ipero ahí es un mundo de gente, en la ruta esa! (Entrevista a trabajador tucumano, 2012).
\end{abstract}

Entre los trabajadores que se reúnen en la ruta se encuentran mujeres y varones de todas las edades, aunque predominan los varones jóvenes y adultos, seguidos por personas mayores y otras muy jóvenes, con la excepcional presencia de niños que acompañan a sus madres.

Todas las mañanas y aún en penumbras, quienes se reúnen en este espacio se disponen a comenzar otra jornada de trabajo. A medida que las personas se van reuniendo, el clima calmo da paso a un intenso bullicio en el que predominan los ruidos de motores que arrancan, se mueven o frenan, bajo los cuales se escuchan las conversaciones y preguntas de los trabajadores, y los cuadrilleros que intentan coincidir mediante sus negociaciones. Sobre los márgenes de la ruta se van estacionando una amplia variedad de medios de transporte, que sirven para trasladar a los trabajadores a los campos de cultivos. Mientras los cuadrilleros estacionan sus vehículos sobre un costado del camino, los trabajadores recorren la ruta de un extremo al otro, en general comenzando por un margen y regresando por el otro, para preguntarle a cada intermediario la opción laboral que ofrece. En este marco, los trabajadores valoran con particular detenimiento la búsqueda de aquellas actividades en las que ya tienen mayores capacidades o destrezas, hecho que les permite elevar los rendimientos y obtener mejores remuneraciones. "Mirá, ahora que está el tomate, la cebolla, la uva y el ajo. Los [trabajadores] que son rápidos para el ajo, se van al ajo. Los que son rápidos para el tomate, se van al tomate. Eligen trabajar en lo que pueden ganar más" (entrevista a trabajadora hija de bolivianos, 2012).

Como postulan Mingo y Berger (2009), la idea de un mayor rendimiento orienta en muchas circunstancias las preferencias de los trabajadores. Muchos entienden que "ganan más" en las actividades que se remuneran a destajo, ya que pueden obtener mayores ingresos por las destrezas que han adquirido.

Frente a esta variabilidad de ofertas laborales y destrezas particulares, se advierte un frenético trajín entre los trabajadores por el poco tiempo de que disponen para obtener algún trabajo que cubra sus expectativas. Muchos conversan entre ellos, preguntan y se asesoran sobre las distintas opciones, dado que no es difícil marearse ante tanto movimiento. En este caso, son los "recién llegados" los que parecen contar con mayores dificultades para elegir, dado que no sólo desconocen a los intermediarios, sino que también ignoran las dinámicas de funcionamiento de estos segmentos laborales.

Es frecuente que las conversaciones entre cuadrilleros y trabajadores refieran a la localización, forma de pago (al día o al tanto) y monto de pago por día, ficha o unidad de producto. Otro dato importante para los trabajadores se refiere al momento en que se efectúa el pago por cada actividad -si al finalizar la jornada o durante el próximo fin de semana-, ya que en muchos casos se prioriza la búsqueda de actividades que se paguen el mismo día de efectuada la labor.

Los trabajos ofrecidos por los intermediarios que confluyen en la $\mathrm{RPN}^{\circ} 15$ incluyen una amplia variedad de actividades agrícolas estacionales, tanto en empresas de gran tamaño como en pequeños establecimientos dirigidos por productores, contratistas o chacareros menos capitalizados, localizados en diversos puntos del territorio provincial.

En Ugarteche hay mucho trabajo, entonces uno puede elegir en la ruta qué conviene más, para dónde salir (...) de Ugarteche salen cuadrillas para todos lados: para la uva, la construcción, el ajo, la fruta. De acá llevan gente para todas partes (Entrevista a trabajador boliviano, 2013).

Todas estas labores estacionales son ofrecidas en la $\mathrm{RPN}^{\circ} 15$ por una amplia variedad de intermediarios. Algunos son cuadrilleros independientes que arreglan con distintas explotaciones productivas; otros se 
vinculan a empresas de terciarización del personal (cooperativas de trabajo y Agencias de RRHH) o a bodegas o explotaciones agroindustriales; otros son pequeños productores, contratistas o chacareros que reclutan trabajadores para sus fincas. Una porción importante de los intermediarios residen en Ugarteche; otros provienen de otras áreas de la provincia. De acuerdo con nuestros registros de campo, los distintos actores que operan en la ruta acusan, además, diversos grados de formalidad en el desenvolvimiento de sus actividades, tanto en lo referido a las condiciones de transporte como al registro de la mano de obra estacional.

Acá el trucho está autorizado. Nosotros hacemos transporte. Pero como ser, esas camionetas, no tienen un seguro, no tienen nada. Los llevan como chanchos (conversación con cuadrillero local, $\mathrm{RPN}^{\circ} 15,2012$ ).

En algunos casos los cuadrilleros solicitan ciertos requisitos a los trabajadores, de acuerdo a perfiles laborales preestablecidos en sus acuerdos con los empresarios/productores. Entre los más habituales está la solicitud de una fotocopia del Documento Nacional de Identidad (DNI) y el Código Único de Identificación Laboral (CUIL), a fin de que la empresa o intermediario puedan registrar al personal contratado. Esta solicitud no implica necesariamente que los trabajadores sean registrados en todos los casos, sino la seguridad de que esa posibilidad existe, frente a cualquier control por parte de la Agencia Fiscal de Ingresos Públicos (AFIP) o la Subsecretaría de Trabajo. Aun así, la presencia de trabajadores que no cumplen con estos requisitos, dificulta el reclutamiento para algunos cuadrilleros y limita las posibilidades laborales para los trabajadores migrantes que no cuentan con esta documentación: "y aquí vienen todos sin documentos, vienen con la "visa" [de turista/residencia transitoria], pero no les sirve para trabajar" (entrevista al presidente de la colectividad boliviana de Ugarteche, 2011).

Los migrantes estacionales que se aventuran desde Bolivia suelen articularse a las cosechas agrícolas de manera informal o "en negro", porque, en la mayoría de los casos, no cuentan con la documentación requerida para efectuar su registración ${ }^{9}$. Por ello, la opción más difundida entre quienes no cuentan con esta documentación reside en trabajar junto a los cuadrilleros que no solicitan estos papeles, o bien agenciarse fotocopias del documento de algún familiar, amigo o pariente hasta tanto ellos consigan tramitar los propios. "En realidad se piden prestado los papeles, eso en realidad. Por mí no está tan mal si entre ellos se ayudan. Si no nadie los ayuda" (entrevista a cuadrillero sanjuanino residente de Ugarteche, 2012).

Además de estos requisitos, resulta frecuente que los cuadrilleros o productores que ofrecen las distintas labores se asesoren sobre las procedencias de los trabajadores y sus habilidades para trabajar en las actividades que ellos solicitan, a fin de seleccionar perfiles acordes a sus requerimientos.

Por su parte, los trabajadores deben acudir a la ruta con la comida y el agua que consumirán durante la jornada de trabajo. Corre por su cuenta también la provisión de distintas herramientas de trabajo, principalmente tijeras, cuchillos, ganchos y guantes, que no son proporcionados por el cuadrillero ni por la empresa, y que resultan indispensables para efectuar las distintas tareas que se demandan.

Hasta aquí hemos contextualizado a la $\mathrm{RPN}^{\circ} 15$ como espacio informal de enganche de trabajadores para las actividades agrícolas en Mendoza, mostrando las inquietudes, preguntas, preferencias y requisitos tanto de los obreros como de los cuadrilleros que allí se concentran. En adelante profundizamos el análisis de las negociaciones por el precio del destajo en las actividades agrícolas estacionales que se suceden a lo largo del ciclo anual.

\section{EL “PRECIO DEL DESTAJO” Y LAS NEgociaCiONES EN LA RPN¹5}

De acuerdo con Marx (1986), la remuneración a destajo se encuentra presente en los estatutos obreros de Europa desde el siglo XIV, aunque cobra verdadero auge en el período manufacturero (1797-1815). Este tipo de remuneración sirve como resorte para prolongar la jornada de trabajo y reducir el salario.

En la lógica del mercado laboral, esta forma de remuneración reconoce un componente que refiere al precio del producto y se asienta sobre una noción más o menos compartida de lo que "es justo" en la distribución 
de ese valor (Rau, 2005). Esto se hace presente en el momento de la negociación de la paga y funciona sobre la base de los conocimientos que demandantes y oferentes de trabajo poseen acerca de las condiciones de producción.

Una particularidad de esta forma de remuneración es que hace referencia a una dimensión cualitativa del trabajo, que, sin embargo, tiene consecuencias cuantitativas sobre el salario que perciben los trabajadores (Rau, 2005). Aquí radica la importancia de recuperar la dimensión "temporal" necesaria para determinar el precio efectivamente abonado por la fuerza de trabajo, o, en otros términos, el salario que recibe el trabajador por el uso de su capacidad laboral durante un determinado tiempo.

De acuerdo con Rau (2005), a diferencia de las modalidades más corrientes de asalarización -que retribuyen a los trabajadores la transferencia de su capacidad laboral en la medida del tiempo en que ésta estuvo disponible para ser usada productivamente por el comprador-, en la modalidad de pago a destajo, ese tiempo se mide en la materialización ya concluida del uso de la fuerza de trabajo en unidades de producto. "Aquí el destajo mismo constituye la dimensión cualitativa del trabajo, pues determina la forma en que una labor deberá ser realizada para producir aquella obra en que se reconoce y cuantifica” (Rau, 2005, p. 455).

De este modo, la intensidad del trabajo se encuentra condicionada en estas modalidades por la forma misma del salario a destajo. Así, ante una variación del destajo, se producirá una alteración del tiempo de trabajo ajeno objetivado en los productos que sirven para cuantificarlo, y, mientras no se trasladen estas variaciones al pago, se operará una alteración cuantitativa del salario percibido por los trabajadores. Por ello, el precio del destajo se halla sujeto a constantes negociaciones, dado que las condiciones sobre las que se fijan los acuerdos varían constantemente entre una explotación agropecuaria y otra. Para cerrar dichos acuerdos se tiene en cuenta si las fincas tienen muchos o pocos frutos, si estuvieron bajo el influjo de algunas inclemencias climáticas, si el corte es manual o con tijera o si el sistema de organización del trabajo se realiza de una u otra forma (Aparicio y Alfaro, 2001).

En las cosechas agrícolas de Mendoza, las condiciones de venta de la capacidad laboral de los trabajadores se encuentran determinadas por el precio del destajo. Es en torno a este precio que se negocia la paga de los trabajadores. Este monto ocupa un lugar similar al que ocuparía la negociación sobre el salario en otros ámbitos. Pero, en rigor, el precio del destajo no constituye todavía el salario, sino una medida estimativa que permite evaluar el monto susceptible de ser alcanzado, de acuerdo a las habilidades o destrezas de los trabajadores y a las condiciones productivas que encontrarán en las explotaciones donde laboren.

Con relación a estas últimas, se ha visto que una de las preguntas recurrentes que efectúan los trabajadores en la ruta es, por ejemplo, “qqué tal será la uva?". La uva "linda o buena" o "fea o mala” califican condiciones que resultan centrales para estimar el salario que podrá lograrse. Es en torno a ellas que giran las negociaciones iniciales entre cuadrilleros y trabajadores en los espacios de enganche. "Las cosechas donde se gana, por ejemplo, hay fincas donde hay más linda uva, por ahí sacamos rapidito los tachos. Así, eso nos conviene. Sí, porque donde no hay uva, a veces sacamos \$50, \$40, no sacamos, no conviene" (Entrevista a trabajador boliviano, 2009).

Ahora bien, la información recabada también nos ha permitido constatar que las condiciones productivas de una finca no sólo se evalúan en función de la cantidad de frutos de sus plantas, sino además en relación a su tamaño, lo que nos remite a las variedades comunes y finas de uva. Veamos:

[¿Y cuál es la diferencia entre uva mala y buena?] Y... rinde más la buena [¿Son uvas más gorditas?] Claro, como ser, hay muchos finqueros grandes que levantan uvas finas y no te rinden las uvas finas [¿Por qué, porque sacan muy poquito?] Claro, como ser, hay mucha gente de afuera que tiene fincas allá en la calle Barrancas y ellos quieren sacar calidad, ¿no es cierto?, y la gente como nosotros no necesitamos ir a cosechar calidad; nosotros necesitamos ir a cosechar "por cantidad", porque a nosotros nos rinde la cantidad, a nosotros nos pagan por tacho, entonces nos sirve cantidad, no calidad (entrevista a trabajador local, 2009).

Estos comentarios ponen de manifiesto que las transformaciones productivas operadas en la agricultura en las últimas décadas inciden directamente en los salarios de los trabajadores remunerados a destajo. En el 
caso de la producción de vid, las transformaciones productivas se orientan hacia la producción de uvas finas para vinificar y comercializar en los mercados internacionales. Ello ha supuesto la implantación de nuevos viñedos y el trasplante de uvas varietales en fincas antes dedicadas a la producción de uvas comunes.

Paralelamente, las nuevas modalidades promueven el uso de tijera en vez de la cosecha a mano y son más estrictas con la no inclusión de hojas en los tachos. Para los trabajadores esto se traduce en la extensión de los tiempos de trabajo para alcanzar las mismas unidades de producto. Si seguimos las reflexiones de Rau (2005), estas transformaciones habrían supuesto una variación del destajo que ha alterado cuantitativamente el salario. La misma ha sido provocada por el cambio cualitativo de aquello que se reconoce como trabajo y por la forma del producto en que ese trabajo se reconoce, es decir, por una transformación en el destajo y la unidad de medida de su pago.

Si miramos con detalle nuestro caso de estudio, la transformación del destajo ha supuesto además desechar una mayor cantidad de hojas y palos, lo que incrementa el tiempo; paralelamente, esa mayor cantidad de hojas desechadas queda fuera de la medida que da lugar al pago. Se trata entonces de una nueva unidad de medida que reconoce, en cada tacho cosechado, el uso de la fuerza de trabajo durante una mayor cantidad de tiempo, lo cual equivale a decir que la fuerza de trabajo se abona a un menor precio.

Además de la "cantidad" y el "calibre" de la uva, la "extensión/dimensión" de las explotaciones productivas incide en las negociaciones por el monto del destajo.

Todo el mundo dice eso, si es grande, no te paga, porque si tenés una finca chica o intermedia, están pagando hasta $\$ 8$ el tacho, y en las grandes $\$ 5$. Y vos decís, “¿cómo el mediano lo hace y el grande no?”. El grande mientras más tiene, más quiere, ese es el problema. Ellos tienen más hectáreas y se agarran de eso, de que la gente va a estar más tiempo trabajando. Los chicos, que trabajaron todo el año, prefieren pagar lo que sea para sacar la producción y ya venderla y empezar a recuperar un poco ¡Es así el tema! (comentario de un cuadrillero local en la RPN¹5, 2012).

Como lo testimonia este fragmento, las explotaciones de mayor tamaño encuentran en su extensión un elemento de negociación que no poseen los productores más pequeños, lo que les permite disminuir el precio del destajo compensándolo con una mayor prolongación del tiempo de trabajo en la explotación. Esta última condición es frecuentemente utilizada por algunos cuadrilleros para captar mano de obra, dado que permite enfatizar la "mayor estabilidad" que alcanzarán los trabajadores, aunque ello pueda redundar en un menor monto por tacho cosechado y en menores salarios por jornada de trabajo.

Por ejemplo, se analiza de dos maneras: una, tiene buena uva; segundo, tiene tres meses de cosecha. Entonces la gente analiza, me voy, hago $\$ 100$ por día, pero tengo 3 meses que me quedo ahí. Otros dicen no, yo me voy porque en otro lado me pagan $\$ 5$ y estoy ganando $\$ 150$ por día, y se van y en 10 días se terminó la cosecha. O sea, son puntos diferentes que se priorizan (entrevista a cuadrillero, Ugarteche, 2012).

Para algunas trabajadoras que residen de forma permanente en los barrios, la mayor "estabilidad" en las explotaciones vitivinícolas de gran inversión de capital resulta valorada positivamente porque les permite acceder a ciertos beneficios sociales. Reciben ingresos proporcionalmente menores que los trabajadores estacionales contratados "en negro" en tiempos de cosecha, a cambio de una mayor continuidad a lo largo del año y cierta cobertura en las prestaciones sociales ${ }^{10}$.

No obstante, otros trabajadores, habitualmente quienes además son migrantes estacionales, priorizan más el monto de la ficha que la duración o "estabilidad" de la cosecha en una determinada finca, dado que prevén permanecer en la localidad sólo por algunos meses, y en muchos casos no poseen la documentación necesaria para acceder a empleos registrados y/o "más estables", además de que no podrían gozar de los beneficios sociales por los que se les efectúan dichos descuentos al retornar a Bolivia. Evidencian entonces mayores niveles de rotación entre intermediarios y trabajos, en busca de lograr las mejores oportunidades durante la temporada en Mendoza.

Otro motivo por el que muchos migrantes evitan la registración es porque la misma supone la pérdida en las capacidades para negociar un mejor "precio del destajo". 
Los cuadrilleros que llevan mucha gente son los que llevan “en negro”, porque ellos dicen “queremos \$5” y el patrón les dice “sí, bueno, está bien”. En cambio a nosotros nos aumentan poco porque estamos “en blanco" (...) Mi hermano, viste, es ligero, él trabaja ["en negro"] con un patrón de por allá nomás y hasta $\$ 400$ saca por día cosechando uva. Sí, es que los ligeros sí pueden hacer una diferencia en esta época, porque ya después trabajás “todo al día” (entrevista a trabajadora local, hija de bolivianos, 2012).

Si bien se ha detectado que algunos trabajadores ya radicados optan por una mayor "estabilidad" y "cobertura" en fincas de mayor tamaño y capital, esto no siempre es así. En ciertos casos se ha podido constatar que para algunas trabajadoras resulta más conveniente desempeñarse en fincas más pequeñas, dado que son las que generalmente incrementan el monto de la ficha frente a la urgencia que poseen por vender su producción, además de contar con menores capacidades de negociación de acuerdo a su tamaño. En este sentido, se destaca el mayor rendimiento que se puede alcanzar frente a la presencia de una menor cantidad de trabajadores, como además el mejor trato y las menores exigencias respecto de las fincas más grandes, aunque ello implique una mayor rotación entre lugares de trabajo y el predominio de relaciones laborales informales. Sumado a ello, en muchos casos las fincas de menor tamaño se orientan a la producción de variedades comunes, de mayor calibre por grano, lo que contribuye a incrementar el rendimiento en la actividad de cosecha.

[¿Y me decía que le gusta más ir a cosechar a fincas más chicas?] Sí, claro [¿Y por qué?] Y rendimos más, más poca gente llevan, porque fincas grandes llevan mucha gente pa' hacerlo rápido y no rinde tanto. En fincas chiquitas es menos uvita pero rendimos más [¿̇se sacan más plata?] Sí (...) mejor nos tratan, pero en fincas grandes cortitos nos tienen (...) nos piden que nos apuremos, quieren que rindamos más (entrevista a trabajadora boliviana, 2009).

Hasta aquí nos hemos referido a la variabilidad en las condiciones productivas en la producción de vid y su incidencia en la definición del monto del destajo por el que son remunerados los trabajadores tomando en consideración algunas categorías emergentes del trabajo de campo. Entre éstas se destacan la uva "buena" y "mala", definidas en relación a la "cantidad" y "calibre" del fruto y a la "extensión/dimensión" de las explotaciones/empresas ${ }^{11}$. Vemos así que las negociaciones que tienen lugar en la RPN 15 envuelven una amplia variedad de aspectos que son tomados en cuenta por intermediarios y trabajadores. Algunos refieren a las destrezas adquiridas para el desempeño de determinadas actividades, otros se relacionan a requisitos necesarios para trabajar (DNI y N ${ }^{\circ}$ de CUIL), otros refieren a las condiciones productivas de las explotaciones ("buenas" y "malas"), a las que se suman las crecientes exigencias motivadas por alcanzar los estándares de calidad, que en general incrementan el tiempo de trabajo pero no la remuneración.

En el marco de este conjunto de elementos en juego, no resulta extraño que las negociaciones iniciales en la $\mathrm{RPN}^{\circ} 15$ operen de forma dinámica e involucren intercambios, tanto entre trabajadores e intermediarios - para asesorarse por las condiciones productivas y los arreglos a los que han arribado con los encargados de las distintas fincas-, como entre los mismos trabajadores - para buscar recomendaciones o sugerencias, tanto sobre las distintas opciones de trabajo disponibles en la ruta como acerca de los cuadrilleros que allí se reúnen-.

En parte por la variabilidad y dinamismo en las relaciones entre los actores que confluyen en estos espacios, pero también por la extendida informalidad que las caracteriza, las negociaciones iniciales que tienen lugar en los espacios de enganche implican el establecimiento de ciertas relaciones de confianza entre sus participantes. Los trabajadores terminan conociendo a la mayoría de los cuadrilleros, y éstos, a su vez, a los "buenos trabajadores". Los cuadrilleros tratan de buscar "la mejor gente" o a "los trabajadores que responden". Como ya referenciamos, en estos contextos de estudio, tanto los migrantes bolivianos como quienes responden a su estereotipo reciben una "mejor visibilización", lo que facilita su articulación a estas actividades (Moreno, 2015; 2017).

Entre las estrategias que ponen en marcha los cuadrilleros para asegurarse esta mano de obra, la promesa de conseguir "buenas cosechas" resulta la más habitual, dado que suelen ser reconocidos entre los trabajadores por sus "contactos". Asimismo, el intento por estrechar vínculos viene acompañado de relaciones 
paternalistas, que se asocian a la conformación de una mano de obra acorde con los requisitos y "gustos" de los empleadores con quienes se vinculan los cuadrilleros (Benencia y Quaranta, 2006).

Por su parte, para los trabajadores que acuden a la ruta, las relaciones entabladas con los cuadrilleros también implican depositar en ellos cierto grado de confianza, dado que no pueden constatar lo que ofrecen hasta tanto lleguen a los campos de cultivo, lo que a veces da lugar a que resulten objeto de diversas formas de engaño. Estas circunstancias motivan que también entre los trabajadores circule información, tanto sobre las distintas opciones de trabajo disponibles en la ruta, como sobre los intermediarios que allí concurren. En este sentido, resulta frecuente que los trabajadores intenten contrastar las opciones laborales ofrecidas por los cuadrilleros, con lo mencionado por otros trabajadores acerca de estos intermediarios y de las fincas a las que llevan a los trabajadores, a fin de ampliar la información disponible para efectuar una mejor elección. "Es como todo, se corre la bola, 'no allá no, porque la uva allá está fea', 'allá está mejor', 'allá pagan tanto', 'allá menos"' (comentario de un cuadrillero local, RPN ${ }^{\circ} 15,2012$ ).

En función de estas circunstancias, los trabajadores con mayor "experiencia" buscan salir con cuadrilleros "conocidos", "cumplidores", dado que, al no firmar ningún contrato, procuran evitar los inconvenientes relacionados con las dificultades para hacer efectivo el cobro de sus remuneraciones, así como de perder días de trabajo en "malas" cosechas, circunstancias a las que quedan más expuestos inicialmente los "recién llegados".

Sin embargo, las prácticas de "engaño" encuentran cierto límite entre los cuadrilleros que poseen intenciones de permanecer trabajando en este espacio, dado que la información circula entre los trabajadores, sobre todo para difundir los nombres de aquellos que incumplen su palabra, lo que se visibiliza en la ruta con la presencia de camionetas o Traffics que no alcanzan a reunir suficientes trabajadores.

"[è con los cuadrilleros cómo es la relación?] Hay algunos malos, algunos buenos, siempre es así con los cuadrilleros [esi paga es bueno, no? ¿Hay alguno que se va sin pagar?] Sí, eso pasa, pero acá la mayoría paga porque si no se quedan sin gente" (entrevista a trabajador boliviano, 2012).

En función de la dinámica de estas relaciones sociales, algunos cuadrilleros se esfuerzan por conseguir "buenas cosechas", hecho que les permite ampliar su red de contactos, dado que saben que los trabajadores los reconocen principalmente por este factor, que al mismo tiempo les permite seleccionar "la mejor gente". Asimismo, cuando las condiciones productivas de los predios para los que reclutan gente no son óptimas, algunos prefieren "sincerarse con los trabajadores", para evitar conflictos posteriores en los lugares de trabajo y evadir la difusión de una "mala imagen” que luego les dificulte reclutar mano de obra. ";Noo!, desde ya te digo que es uva mala, es una changuita nomás"(Conversación entre cuadrillero y trabajadores, $\mathrm{RPN}^{\circ} 15,2012$ ).

Otra opción que muchos cuadrilleros utilizan para facilitar el reclutamiento de la mano de obra consiste en negociar con los empleadores por un aumento en el monto del destajo en los casos en que existan malas condiciones productivas. No obstante, estas prácticas encuentran ciertos límites, dado que muchos trabajadores suelen asociar los montos "muy altos" con cosechas "muy malas".

Sí, hay lugares buenos... yo todavía no agarré ni una uva "buena", solamente "regulares". Y acá se saben todo, cuando te dicen "che, vamos a la uva” en la mañana, "¿cuánto estás pagando?”. “\$7”. “Uhh!, debe estar malísima”. Entonces el precio normal es de $\$ 4,50$ o $\$ 5$, cuando está más o menos regular, viste. Y ya cuando te dijeron de $\$ 6$ para arriba, ya es porque la uva está mala (Entrevista a trabajador procedente de Jujuy, 2012).

En este marco, se advierten las notables capacidades de negociación que deben adquirir los cuadrilleros para arreglar al mismo tiempo con las empresas/productores y con los trabajadores, dado que deben responder a las expectativas de sectores cuyos intereses son divergentes, con la finalidad de cumplir con su labor.

Ahora bien, si consideramos la estacionalidad propia de estos mercados laborales y los picos en la demanda de trabajo que se ocasionan en determinados períodos del ciclo anual, estas negociaciones se complejizan.

La información construida nos ha permitido constatar que la demanda cíclica de trabajo plantea momentos de "alta" y momentos de "baja" en la contratación de los trabajadores, y que esta situación genera capacidades diferenciales de negociación entre los actores involucrados. A lo largo del ciclo anual, la demanda 
de trabajo crece a partir del mes de octubre y se prolonga hasta el mes de mayo (Tabla 1). No obstante, entre febrero y abril se generan verdaderos "cuellos de botella" por los mayores requerimientos de fuerza de trabajo estacional y se propicia una importante competencia por los trabajadores disponibles entre los diferentes sectores y actividades. En este contexto, los trabajadores acceden a una mayor cantidad de ofertas de trabajo y sus capacidades de negociación mejoran frente a empresas e intermediarios urgidos por levantar las cosechas a tiempo. En este marco, los cuadrilleros utilizan algunas estrategias para proveerse de la mano de obra necesaria, entre las que el aumento en el monto del destajo o el pago durante la misma jornada son las más frecuentes.

Porque una vez que ya empezó la uva, todos quieren sacar a la misma vez, y hay veces que no hay tanta gente como para llevar a todas las fincas (...) entonces, ponele, buscás un precio más alto o que te pague la gaseosa o que te pague el viernes, cosas así te ofrecen los cuadrilleros para conseguir la gente (trabajador local, hijo de migrantes bolivianos, 2012).

Asimismo, durante estos períodos se restringe la posibilidad de que los productores e intermediarios seleccionen perfiles de trabajadores que se consideran ideales para el desarrollo de ciertas tareas. Esto significa que cuando existen urgencias por realizar algunas labores culturales en tiempo y forma, se desdibuja la organización del proceso de trabajo en términos de requisitos preestablecidos, dado que se prioriza la obtención de mano de obra.

El otro día nomás unos me pidieron papeles (...) Pero ahora que ya empezaron a levantar la cosecha todos, no les calienta, los cargan igual y se los llevan igual. Se los llevan igual y se olvidan de los papeles. Ellos quieren levantar la cosecha, así que el resto no les importa (entrevista a trabajador procedente de Jujuy, 2012).

De modo inverso a lo que sucede en estos "picos", durante el resto del ciclo anual el mercado laboral se encuentra más sobreofertado por una menor presencia de intermediarios y una disminución en la demanda de trabajo. Esto ocurre aunque durante el invierno desciende la oferta de trabajadores, porque muchos migrantes estacionales regresan a sus pueblos o parten hacia otras regiones. En todas las temporadas se renuevan los flujos con "gente nueva" o "recién llegados", al tiempo que algunos siempre "se van quedando" y prolongan paulatinamente su permanencia en la zona. En este marco, durante el resto del ciclo anual, empresarios y cuadrilleros restablecen su poder para seleccionar perfiles en la fuerza de trabajo, lo que favorece una mayor subordinación de los trabajadores al proceso productivo (Rau, 2005).

...esta época es de "changueo" digamos, hasta abril, donde el obrero se hace valer, después es a la inversa. En mayo las empresas se hacen valer, y es que al no haber fuentes de laburo, por lo que quieran pagar "voy y trabajo" (...) Así es el sistema, viste. Si yo estoy apurado por levantar mi cosecha y no tengo gente, entonces tendré que pagar lo que me piden, y después, cuando los otros no tienen trabajo, "bueno, ahora me toca a mí" dice la empresa (entrevista a trabajador boliviano, 2012).

Estas oscilaciones en la demanda se hacen visibles en uno y otro momento en la misma $\mathrm{RPN}^{\circ} 15$. Por ejemplo, durante el trabajo de campo en los meses de diciembre y enero, a medida que pasaban las horas, los vehículos se completaban y quedaban sobre la ruta muchos trabajadores sin haber sido enganchados. De forma contrapuesta, durante los meses de cosecha de uva, quienes quedaban esperando en la ruta eran los cuadrilleros, dado que los trabajadores encontraban trabajo rápidamente.

Ahora, sí, hoy yo estoy vacío. Ya no hay gente [Han quedado un montón de camionetas vacías èy sin trabajadores cómo hacen? ¿Van a buscar a otro lado?] No, ya fue. Que haga lo que quiera, que busque él, el patrón (comentario de un cuadrillero local, $\left.\mathrm{RPN}^{\circ} 15,2012\right)$.

Estos vaivenes en la demanda de trabajo no hacen más que poner de relieve la elasticidad y dinamismo que adoptan estos segmentos laborales en la agricultura y el modo en que la eventualidad e informalidad en la vinculación entre oferta y demanda permiten desarrollar variadas estrategias de parte de intermediarios como de trabajadores. 


\section{REFLEXIONES FINALES}

En este trabajo nos propusimos analizar las modalidades de negociación que entablan cuadrilleros y trabajadores en un espacio de contratación informal emplazado en el distrito de Ugarteche (Luján de Cuyo). El recorte propuesto sobre el problema de estudio permitió poner de relieve de forma novedosa la construcción de un segmento del mercado de trabajo local, que satisface las necesidades de mano de obra de una agricultura diversificada, que se organiza por medio de distintas lógicas y se orienta a diversos mercados, para lo cual recurre a un conjunto heterogéneo de trabajadores que convergen y se relacionan en sitios específicos y a través de distintas modalidades de intermediación.

A partir del trabajo de campo en la $\mathrm{RPN}^{\circ} 15$, exhibimos parte de la complejidad que revisten las formas de enganche de los trabajadores estacionales en Mendoza, no sólo por la multiplicidad de acuerdos con diverso grado de formalidad y entre distintos actores - que se apartan del modelo clásico patrón/obrero-, sino además por la variabilidad en las condiciones productivas sobre las que se establecen dichas negociaciones.

En este contexto, destacamos que las condiciones de venta de la capacidad laboral de los trabajadores se encuentran determinadas por el "precio del destajo", monto que se negocia en función del estado de las plantaciones o productos a ser procesados, y a partir de ciertos parámetros, como la cantidad y calibre de los frutos, así como la extensión de las fincas, aspectos que toman cuerpo con ciertas clasificaciones locales ("uva linda", "uva fea", por ejemplo).

Además, el trabajo de campo nos permitió constatar que la demanda cíclica de trabajo da lugar a momentos de "alta" y de "baja" en la demanda de trabajo, lo que genera diferenciales capacidades de negociación entre los actores involucrados en estos segmentos laborales. En este marco, describimos algunas estrategias desplegadas por los cuadrilleros para conseguir "los mejores trabajadores", así como las desplegadas por los trabajadores, quienes difunden información valiosa acerca de los intermediarios y sus ofertas, en un juego interminable de negociaciones y renegociaciones que ponen de relieve la capacidad de agencia cotidiana de estos actores.

Para efectuar este abordaje resultó fundamental considerar las prácticas y condiciones locales que se articulaban con dinámicas globales, como los desplazamientos migratorios en el contexto de desarrollo de la agricultura capitalista en distintas regiones de América del Sur. Desde esta perspectiva, la localidad provee el contexto de oportunidades y restricciones en las cuales se insertan los trabajadores migrantes (Sassen, 2007). En la agricultura de Mendoza esto se ha expresado en la construcción de un segmento laboral disponible para ciertos migrantes, que ubica en primer plano a los trabajadores bolivianos y al juego de relaciones que se propician dentro de este segmento del mercado laboral.

\section{REFERENCIAS}

Alfaro, M. I. (1999). Los espacios para la negociación laboral en la citricultura tucumana: Actores y Estrategias. Disciplinamiento, conflictividad y resistencias. Revista Estudios del trabajo, 18, 39-59.

Alfaro, M. I., y Rau, V. (2005). La conflictividad social en mercados de trabajo rurales intermediados: los casos del mercado de trabajo yerbatero misionero y de la citricultura tucumana. $7^{\circ}$ Congreso Nacional de Estudios del Trabajo. ASET, Buenos Aires, Argentina. Recuperado de https://www.aset.org.ar/congresos/7/15005.pdf

Altschuler, B. (2016). Desigualdades y fronteras sociales en la configuración de la vitivinicultura mendocina (Tesis Doctoral). IDES-UNGS, Buenos Aires.

Aparicio, S., y Alfaro, M. I. (2001). Las múltiples negociaciones para acceder al trabajo. V Congreso Nacional de Estudios del Trabajo, ASET, 1-4 de agosto.

Benencia, R. (2008). Migrantes bolivianos en la periferia de ciudades argentinas: Procesos y mecanismos tendientes a la conformación de territorios productivos y mercados de trabajo. En S. Novick (compiladora), Las migraciones en América Latina. Politicas, culturas y estrategias (pp. 13-30). Buenos Aires: Catálogos. 
Benencia, R., y Quaranta, G. (2006). Mercados de trabajo y relaciones sociales: la conformación de trabajadores agrícolas vulnerables. Sociología de Trabajo, (nueva época), 58.

Berger, M., y Mingo, E. (2012). Condiciones de reproducción e inserciones laborales de los trabajadores agrícolas en el Valle de Uco, provincia de Mendoza. Theomay, 24, 115 - 140

Bocco, A. et al. (2007a). La trama vitivinícola en la provincia de Mendoza. En M. Delfini et al. (Compiladores), Innovación y empleo en tramas productivas de la Argentina (pp. 43 - 91). Buenos Aires: Prometeo libros.

Bocco, A. (2007b). Transformaciones sociales y espaciales en la vitivinicultura mendocina. En M. Radonich y N. Steimbreger (compiladoras), Reestructuraciones sociales en cadenas agroalimentarias (pp. 111 - 144). Buenos Aires: La Colmena

INDEC Instituto Nacional de Estadísticas y Censos de la República Argentina, Dirección de Estadísticas e Investigaciones. (2012) Censo Nacional de Población, Hogares y Viviendas 2010.

Ciarallo, A. (2014). "Se vamo" a la de dios". Migración y trabajo en la reproducción social de familias bolivianas horticolas en el Alto Valle del Rio Negro. 1a ed. Córdoba: Centro de Estudios Avanzados.

Courtis, C., y Pacceca, M. I. (2006). Migración y trabajo precario: ęun par desarticulable?. e-misférica, 3-2.

DEIE Dirección de Estadísticas e Investigaciones Económicas (2010-2011), Estadísticas Económicas, Sector agropecuario. Participación relativa de la producción agricola por subsector. Mendoza.

Denny, T. (1978). Storytelling and educational understanding, address delivered at National Meeting of International Reading Associatión. Houston, Texas.

Fabio, J. F. (2010). Regulación social de la transitoriedad. El mercado de trabajo en la producción de uvas en Mendoza, Argentina. Cuadernos de Desarrollo Rural, 7(64), 33-57.

Génova, N. (2006). The everyday civil war. Migrant working men, within and against capital. Ethnography, 7, 243-267

Giddens, A. (1979). Central problems in social theory: action, structure and contradiction in social analysis. Berkeley: University of California Press.

Hammersley, M., y Atkinson, P. (1994). Etnografía. Métodos de investigación. Buenos Aires: Paidós.

Herrera Lima, F. (2005). Vidas itinerantes en un espacio laboral transnacional. Méjico: Universidad Autónoma Metropolitana.

IDR Instituto de Desarrollo Rural (2006). Tipología de Productores rurales de la provincia de Mendoza.

Kearney, M. (2008). Lo global y lo local: La antropología de la globalización y el transnacionalismo. En D. Hiernaux y M. Zárate (eds.), Espacios y transnacionalismo (pp. 51-87). México: UAM y editorial JP.

Marx, K. (1986) [1867]. El Capital. Crítica de la Economía Política. México, D. F.: Fondo de Cultura Económica.

Meillassoux, C. (1985). Mujeres, graneros y capitales. Economía doméstica y capitalismo. México: Siglo XXI.

Mingo, E., y Berger, M. (2009). Asalariados rurales en el Valle de Uco (Mendoza, Argentina). Mundo Agrario. Revista de Estudios Rurales, 10(19).

Moraes Silva, M. A. (1999). Errantes do fim do século. São Paulo: Fundação Editora da UNESP (Prismas)

Morberg, M. (1996). Myths That Divide: Immigrant Labor and Class Segmentation in the Belizean Banana Industry. American Ethnologist, 23(2), 311-330.

Moreno, M. S. (2013). Humildes, sumisos y trabajadores. XRAM Reunión de Antropólogos del MERCOSUR, Córdoba.

Moreno, M. S. (2015). Gente humilde, gente trabajadora. Identificaciones étnico-nacionales de los bolivianos en el mercado laboral agrícola de Mendoza. En C. Pizarro (ed), Bolivianos y bolivianas en la vida cotidiana cordobesa: Trabajo, derechos e identidad en contextos migratorios (pp. 101 - 132). Córdoba: Universidad Católica de Córdoba, EDUCC.

Moreno, M. S. (2017). De pasaditas nomás voy. La participación de los migrantes bolivianos en las cosechas agricolas de Mendoza. Estudio de caso a partir de una etnografía multilocal (Tesis doctoral inédita). Cuyo, FCPyS, UNCuyo.

Neiman, G. (2010). Los estudios sobre el trabajo agrario en la última década: una revisión para el caso argentino. Mundo Agrario, 10(20). Disponible en: http://www.memoria.fahce.unlp.edu.ar/art_revistas/pr.4185/pr.4185.pdf 
Neiman, G., Bardomás, S., Berger, M., Blanco, M., Jiménez, D., y Quaranta, G. (2006). Los asalariados del campo en la Argentina: Diagnóstico y Políticas. Buenos Aires: Secretaría de Agricultura, Ganadería, Pesca y Alimentación, PROINDER.

Neiman, G., y Blanco, M. (2003). Modalidades de contratación y empleo de la mano de obra estacional en el cultivo de vid. Trabajo presentado en $6^{\circ}$ Congreso Nacional de Estudios del Trabajo (agosto), UBA, Buenos Aires: Fondo de Cultura Económica.

Neiman, G. y Bocco, A. (2005). Estrategias empresarias y transnacionalización de la vitivinicultura argentina. En J. Barbosa Cavalcanti y G. Neiman (compiladores), Acerca de la globalización en la agricultura (pp. 205-227). Buenos Aires: Ediciones Ciccus.

Pedone, C. (1999). Territorios marginales y globalización. Organización social agraria en un área del margen del Oasis Norte, Mendoza (Argentina). Scripta Nova, Revista Electrónica de Geografía y Ciencias Sociales, 45(12) Disponible en: http://www.ub.edu/geocrit/sn-45-12.htm

Pizarro, C. (2010). Sufriendo y resistiendo la segregación laboral: experiencias de inmigrantes bolivianos que trabajan en el sector hortícola de la Región Metropolitana de la Ciudad de Córdoba. Trabajo presentado en Seminario Internacional sobre Migraciones Internacionales Contemporáneas: Estudios para el Debate. Buenos Aires.

Pizarro, C. (ed.) (2011). SER BOLIVIANO en la Región Metropolitana de la ciudad de Córdoba. Localización socioespacial, mercado de trabajo y relaciones interculturales. Córdoba: Universidad Católica de Córdoba.

Pizarro, C. (2014). Bolivian woman who have moved with men to Córdoba and Buenos Aires, Argentina: Interseccion of inequalities in their migratory trayectories, labor experience and family life. Trabajo presentado en el Annual Meeting of the society for applied Antropology, Albuquerque, USA.

Pries, L. (2000). Teoría Sociológica del Mercado de Trabajo. En E. De la Garza Toledo (Coordinador), Tratado latinoamericano de Sociología del Trabajo. México DF: El Colegio de México - FLACSO - UNAM.

PROINDER Proyecto de Desarrollo de Pequeños Productores Agropecuarios (1996-2003). Encuesta sobre niveles de vida y producción (ENVP).

Rau, V. (2005). Transformaciones en el mercado de fuerza de trabajo y nuevas condiciones para la protesta de los asalariados agrícolas. Jóvenes 6/4/05 11(48), 419-475.

Sanchez Saldaña, K. (2001). Acerca de enganchadores, cabos, capitanes y otros agentes de intermediación laboral en la agricultura. Estudios Agrarios, 17, 61-103.

Sassen, S. (2007). Una sociologia de la globalización. Buenos Aires: Katz Editores.

SAF Secretaría de Agricultura Familiar (2016). Sector Horticola en Mendoza: Caracterización, rol de la agricultura familiar y propuestas para la intervención. Ministerio de Agroindustria. Presidencia de la Nación. Recuperado de http://www.maipuproduce.com/u/archivos/2016/4/7/Informe\%20hort\%C3\%ADcola\%202015.pdf

Tomada, C., y Rigat-Pflaum, M. (1998). Negociación Colectiva ante el Siglo XXI. Aportes para la acción sindical. Fundación Friedrich Ebert, Argentina.

Torres, G. (1997). La fuerza de la ironía. Un estudio del poder en la vida cotidiana de los trabajadores tomateros del occidente de México. México: CIESAS-El Colegio de Jalisco.

Wolf, E. (2005). Europa y la gente sin historia. Buenos Aires: Fondo de Cultura Económica, SA de CV.

\section{Notas}

1 Una versión preliminar de este trabajo fue presentada en las Terceras Jornadas de Sociología de la Facultad de Ciencias Políticas y Sociales de la Universidad Nacional de Cuyo y Pre-ALAS de la provincia de Mendoza, República Argentina. Agradezco los aportes de los comentaristas y asistentes.

2 Es decir, los trabajadores que no son contratados en forma permanente en la agroindustria, o no trabajan de forma exclusiva en la actividad agrícola de Mendoza, sino que se desempeñan a "tiempo parcial" y/o en períodos circunscriptos del año.

3 Si bien los trabajadores que se articulan en las cosechas agrícolas constituyen un grupo heterogéneo, las/os migrantes bolivianas/os resultan un grupo de gran importancia dentro de esta actividad. En esta investigación los consideramos 
especialmente, dado que la revisión bibliográfica para el caso de Mendoza focaliza casi exclusivamente en los trabajadores tucumanos o procedentes de algunas provincias del norte de Argentina, sin mencionar ni estudiar a las/os a trabajadoras/ es bolivianas/os que desde 1950 se insertan en las cosechas.

4 Dada la complejidad del mercado laboral agrícola estacional de Mendoza, sería útil aportar información secundaria sobre el origen, género y edad (entre otras variables) de sus trabajadores. Lamentablemente estos datos no están disponibles para el período de referencia, y sólo se cuenta con fuentes de información secundaria parciales. Por ejemplo, las fuentes que exponen datos sobre migrantes (Censo Nacional de Población y Vivienda 2010) no especificaban sus inserciones laborales, y aquellas que proporcionan información sobre trabajadores agrícolas sólo efectúan estimaciones sobre la cantidad de jornales que se ocupaban en algunas cosechas más fiscalizadas, como la de la vid (Abihaggle, 2010), sin especificar el origen nacional ni el sexo de los trabajadores contratados. Además quedan fuera del análisis todos los trabajadores que acceden al empleo de modo informal.

5 Otro autor que profundiza en las resistencias activas de los trabajadores, aun en condiciones de restricción por su posición y por su condición de clase es Scott (2000). El mismo no fue incluido en este artículo dado que focalizamos en las modalidades de negociación laboral en un espacio de contratación informal, por lo que el par categorial que alumbra el análisis de los datos es el de negociación/conflicto.

6 El caso de estudio se seleccionó con base en sus características de tipicidad e idoneidad, lo que permite ampliar los resultados de este trabajo a otros espacios de contratación informal dentro de la provincia. No obstante, cabe destacar que dentro de la estrategia cualitativa, la búsqueda de la "representatividad" de los datos no es el principal objetivo, dado que se basa en el razonamiento inductivo.

7 Que incluyó a todos los actores que se convocaban en este lugar, es decir, trabajadores e intermediarios, sobre la base de un muestreo intencionado y teórico.

8 No obstante, cabe aclarar que siempre que fue necesario para el análisis y la comparación, se incorporaron datos de entrevistas y observaciones que se efectuaron por fuera de esta unidad de estudio, en el marco de un trabajo de campo más amplio cuyos objetivos superan los propuestos para este artículo.

9 En concreto, los extranjeros que ingresan en nuestro país pueden hacerlo bajo las categorías de residencia transitoria, temporaria o permanente. Para ingresar bajo la categoría de residencia transitoria, los ciudadanos nativos o radicados en los estados parte del Mercado Común del Sur (MERCOSUR) sólo deben presentar en los pasos fronterizos habilitados su cédula de identidad o el pasaporte válido y vigente. Como contrapartida, éstos sólo pueden permanecer en el país por 3 meses y no se les permite realizar actividades laborales permanentes ni temporales. Por ello, para trabajar y residir de manera legal y por un mayor tiempo en Argentina deben tramitar la residencia temporaria, que se les concede por un plazo de 2 años, luego de los cuales deberán tramitar la residencia permanente. Ambos trámites implican la presentación de una mayor cantidad de documentación, cuya gestión supone tiempos y costos difíciles de asumir por aquellos migrantes más vulnerables (Pizarro, 2014).

10 Éstos pueden formar parte del mercado de trabajo primario, pero también se pueden desempeñar en el segmento agroindustrial (bodegas, empacadoras de frutas y hortalizas, etc.); pueden ser estables discontinuos, pero también pueden estar registrados bajo otras categorías, como las de no permanentes, de temporada y eventuales, categorías que contempla la ley 20.744 de Contrato de Trabajo (LCT) (modif. ley de empleo 24.013/91) y el Nuevo Estatuto del Peón Rural (ley 26.727), de acuerdo al análisis efectuado por Fabio (2010).

11 Las producciones de frutales y hortalizas también han surcado procesos sostenidos de tecnificación y búsqueda de calidad en las últimas décadas y, aunque no asistieron a la implantación de nuevas variedades, de todos modos han visto transformados sus requerimientos de mano de obra para las actividades de cosecha. En esta oportunidad no las incluimos en el análisis por cuestiones de espacio. 